\title{
An Assessment of Strengths and Weaknesses of Iranian First Year High School English Coursebook Using Evaluation Checklist
}

\author{
Mohammad Zohrabi (Corresponding author) \\ Department of English Language, Faculty of Literature, University of Tabriz, Tabriz, Iran \\ E-mail:mohammadzohrabi@gmail.com
}

Hossein Sabouri

Department of English Language, Faculty of Literature, University of Tabriz, Tabriz, Iran

E-mail:kassabouri@gmail.com

Raziyeh Behroozian

Aras International Campus

E-mail: Behroozyan216@gmail.com

Received: April 29, 2012

Accepted: May 10, 2012

Published: June 1, 2012

doi:10.5539/ells.v2n2p89

URL: http://dx.doi.org/10.5539/ells.v2n2p89

\begin{abstract}
In spite of remarkable advances in teaching and developing new technologies, textbooks have a very crucial effect in the process of language teaching and learning. This paper evaluates the first year English textbook which is taught in Iranian high schools. For this purpose, textbook evaluation model was employed to conduct the research. The advantages and shortcomings of the textbooks are discussed in detail with reference to 13 common criteria extracted from different material evaluation checklists. The results suggest that one of the main factors for the students' achievement in English language is the ELT textbooks. Throughout the study, Iranian first year high school English textbook was examined with reference to the relevant theoretical background, and the content analysis. The study was carried out at four schools in Tabriz, Iran. The mixed method, a combination of both quantitative and qualitative approaches was used in this study. The data were obtained from a total of 126 language learners, both female and male. It was collected through a questionnaire with 34 close-ended questions which were related to the seven sections of the book including the layout or physical make-up, vocabulary, topics and content, grammar points and exercises, language skills, pronunciation practice, and language function and social and cultural activities. Quantitative data were analyzed through SPSS. Meanwhile, qualitative data were gathered via interview with 14 teachers and selected students. It is realized that there should be enough opportunities for learners to practice the language communicatively. The research findings make it clear that the current material or textbook cannot meet the Iranian students' and teachers' needs and they are not acceptable and desirable for them. It can be concluded that the English textbook 1 is structure-based. So, the writers of the book should modify it by employing more communicative tasks in order to meet the teachers' expectations and students' needs.
\end{abstract}

Keywords: Coursebook, Evaluation, Materials, Checklist, Criterion

\section{Introduction}

Textbooks are a core part of any curriculum, and they are crucial to the teacher so one might assume they are researched, written, and published as unique contributions to advancing knowledge. They have an important influence in the instructional process. ELT textbooks have major function in the current discussion. Sheldon (1988, p. 237) states that "textbooks represent the visible heart of any ELT program". Textbooks are an almost universal component of English language teaching. They are of great value and effect in the process of teaching and learning. Material development and evaluation is a relatively new trend in the field of language teaching. In practical sense, it includes the production, evaluation and adaptation of materials. Tomlinson (2001, p. 66) defines materials as "anything which can be used to facilitate the learning of a language." Constant evaluation of textbooks to see if they are appropriate is of great importance. This process enables us to make informed decisions through which student 
achievement will increase and educational programs will be more successful. The lack of success in achieving students' needs, teachers' expectations and even the experts who try to develop the educational plans, can be related to different instructional elements.

\section{Background of the Study}

According to Giaschi (2000), as a result of more than 60 years of development, English in the world, now, is one of the central components of education. As Crystal (2003) states, the number of people studying English has increased and about $85 \%$ of international organizations benefit from official use of English in the world. Recently, in the Iranian context of ELT, there has been an increase in the teaching of English as a foreign language. Therefore, English is one of the necessary courses in the educational trend and is instructed from guidance school. It should be mentioned that, in Iran, English textbooks are prepared on the basis of the policies of the Ministry of Education.

An overview of the English language teaching in Iran shows that while before the Iranian Islamic Revolution, according to the government's policy, native speakers of English used to teach English language to the students, after the revolution (1979) it is the non-native teachers who teach it. At the moment, Iranian students are to study English as a foreign language for approximately seven years in a way that there is one special book for each grade of these seven years.

\section{Significance of the Study}

The significance of the present research is related to the fact that, by using a checklist, it has a particular potential to examine the strengths and weaknesses of any textbook and the findings can help teachers to replace or balance the effects of book's shortcomings. It can also give directions for modifying English book 1 in the future. Hence, it is necessary to choose and define the relevant criteria by which the merits and demerits of the textbooks are going to be examined. The result of this study can be useful for the English language teachers and educators in Iran. Also, the study can help textbook designers to modify and change English textbooks in the future.

Most teachers and principals of high schools believe that students' success in English language depends on various factors. One of these factors may relate to the features and the quality of textbooks used in the process of English language teaching. The evaluation of the first year English textbook, commonly taught in Iranian high schools, is another significant issue to identify new ways of reforming its quality and ultimately the quality of teaching and learning English in educational system of Iran. This study also attempts to make suggestions in the field of text selection. This suggestion gives teachers a new and real insight into the ways by which they can help students.

\section{Review of Literature}

A textbook is an excellent tool for the performance of the material, an effective reference for learners, a tool or piece of equipment made for a particular purpose, a security device for opinions and activities, a useful manual for novice teachers, and an effective source for displaying the goals of language learning. Davison (1975) suggests that in the foreign language classrooms, the next most important component after the teacher is the textbook.Textbooks present teachers with instructional designs according to the latest research and teaching strategies. Teachers' use of textbooks is beneficial to students. Students benefit from detailed sequence of teaching procedures found in a textbook for presenting the subject matter. According to Razmjoo (2007, p. 2), many students who use textbooks "feel secure and have a sense of progress and achievement". They have a book to relate to all the time, which "makes them more confident and satisfied" (ibid.). A textbook also prepares them with "the opportunity to go back" (ibid.) and practice whenever they want. It can also be used by students for "self-study" and as a reference device. The portability of textbooks allows students to quickly look up answers for immediate questions about a topic or subject matter. Students can also read them in their own time outside the classroom, which may increase their ability to perform better in school.

A good textbook will provide guidelines for interpreting educational standards and setting curriculum guidelines within each school. Textbooks also include practice tests and questions to help students to prepare for examinations and real life situations. Nowadays, many textbooks provide creative learning activities involving cooperative groups, inquiry, problem solving and discovery. Teachers can choose from a range of engaging suggestions and alter them to fit the students' needs. Masuhara, Hann, and Tomlinson (2008) persist that teachers want a student's book which stimulates, fascinates, excites, entertains, inspires, challenges, and helps both students and teachers to develop. They also want to be able to personalize, localize, and adapt the global textbooks to suit their learners in their classrooms. Y1lmaz (2005) offers that teachers should not only rely on the textbook but rather be selective in matching it to the special needs of learners and the defined goals of the course. No textbook is able to answer all learners' needs. It is because each student has different needs. Teachers may feel themselves as mediators without any authority. Textbooks are not perfect and they are only as simple devices for teachers. They are sometimes non-authentic, for 
they do not show the real language use. Teachers' role can become reduced because their important task is to introduce the materials provided by others. Textbooks may sometimes fail to offer real issues.

\section{Importance of Textbooks}

Despite the fact that textbooks are important elements in most EFL classes, it is difficult to define their importance in language classrooms. They are designed for giving cohesion to the process of language teaching and learning by preparing the syllabus for language programmes, giving direction and support, and offering classroom activities and practices to the students. Using only textbooks, without any additional materials is the least suitable method for meeting students' needs.

Textbooks are also a key factor in most language programs. In some classrooms, they are used as the source of language input and language practice for learners. They can also be used as a source of different classroom activities, content of the lessons, and maintenance of the skills balance. In some classrooms, they may apply mainly to add and make the teacher's instruction complete. For some learners, it can be the main source of having contact with the language, separate from information prepared through the teacher. Regarding beginner teachers, it can also be used as a source of teacher instruction. Tomlinson (2003, p. 39) believes that "A textbook helps provide a route map for both teachers and learners, making it possible for them to look ahead to what will be done in a lesson as well as to look back on what has been done". Despite the impact of new technologies, textbooks will doubtlessly continue to play an important role in language teaching and provide a useful source for both teachers and learners. They are seen as sources of achieving learners' needs and matching the aims and objectives of their needs. They will help to equip students to use language effectively for their own purposes. Textbooks and other materials used in language learning, generally, present a certain way of looking at the world. They fulfil an extremely important role in the process of education and English language teaching.

Nunan (1999, p. 98) states that "a textbook is the main component of any instructional program and it is difficult to imagine a class without it..." Cunningsworth $(1995$, p. 7) believes that textbooks have multiple roles in English language classes: they can help to present the written and spoken materials, provide activities, promote interaction, serve as a reference of vocabulary and grammar, act as a source for classroom activities, serve as a syllabus, and offer self-access work or self-directed learning.

A textbook is a tool in the hands of the teacher. It might be regarded as one of the many resources a teacher can draw upon in creating effective lessons. Teachers must know not only how to use it, but also how useful it can be.

If textbooks are seen as instructional tools, they strongly influence the methods. As Richards (2007, p. 251) maintains, materials "provide the students with the main information and the type of the language practice that occurs in the classroom". He (ibid., p. 270) believes that, although materials do not always provide the actual process of teaching, they "represent plans for teaching". Furthermore, materials are the performance of a method and classroom activities are the performance of the materials. Dudley-Evans and St. John (2000, p. 170) suggest four primary functions of using materials in the classroom: "as a source of language, as a learning support, as a motivation and stimulation, and as a reference". Richards and Rodgers (2002, p. 30) offer that "the main aim of materials is to present and practice content, ease interaction between students, and promote learner autonomy". Davison (1975) suggests that in the foreign language classrooms, the next most important component after the teacher is the textbook.

\section{Key Features of Textbooks}

Textbooks can be auditory, kinaesthetic, linguistic, or visual. They can appear in the shape of materials that consist of both printed materials such as books and guidebooks and non-printed ones such as CDs, cassettes or audio materials. Users of materials may consist of learners, teachers, administrators and publishers. Textbooks can be considered as the easiest and most useful language teaching materials. According to Jordan (1997, p. 256), some of the current characteristics of textbooks include: "authenticity, comprehension checks/questions, summarizing, writing tasks, pair work, group discussions, listening activities, note-taking, and glossary of specialist terms".

Materials should be authentic. Mainly, the activities used with such texts should be authentic because using tasks such as answering comprehension questions or filling the gaps would make the texts non-authentic.

In addition, materials should be based on universal topics which are culturally specific, and are present in all cultures at the same time. These topics may include issues such as life experiences, feelings, and relationships. This quality makes learners to become more aware of cultural differences and similarities. Also, textbook materials should be relevant and potentially effective and beneficial to the students.

The material should be learner-centred. That is, to put learners at the center of the learning process. According to Richards (2002, p. 298), learner-centred approaches may be reflected by 'recognizing learners' prior knowledge, 
needs, goals, wishes, learning styles and preferences, views of teaching, and of classroom tasks nature". So, the learners become the main input providers while the teacher's role is facilitator. Therefore, teachers and materials provide only stimulus, a starting point for different approaches and language exposure.

Materials should be flexible in ways that enable learners to develop a variety of skills and learning styles in order to become independent learners. They should also provide learners with the chance of selecting tasks, activities, and approaches, and arranging the materials with learning needs.

Materials should be open-ended. They are open to many different ideas and points of view. In this case, the materials are not based on right/wrong testing and practice. In contrast to questions with limited multiple-choice possibilities, they encourage a variety of interpretations which allow the learner to provide answer in his or her own way. According to Cunningsworth (1995, p. 10), teachers dependency on textbooks decrease "their flexibility" and increase "their contributions, creativity, and innovation".

\section{Textbook Evaluation}

As Zohrabi (2011, p. 216) argues, "Materials, especially coursebooks, need to be evaluated at every stage of the course in order to find their weaknesses and improve them." As Tomlinson (2006) states, no textbook is perfect, since it can be used by different students in different circumstances. In evaluating a textbook, we need to know how it meets learners' needs. Evaluation might vary from one context to another based on the aims, wants, and abilities of the evaluators. Assessment of textbooks is a profitable way of teacher development and gives beneficial perception to the teachers. As Cunningsworth (1998) argues, one reason relates to recognizing strengths and weaknesses of a textbook after its use. In this case, an evaluator can reinforce textbook's weaker points through substitution and change of materials. Also, they can benefit from its strong points. The selection of a new book is the main reason of evaluation.

Hutchinson and Waters (1989, p. 96) state that evaluation of materials should be performed for the purpose of giving an opinion about our materials" suitability to our "particular purpose". Sheldon (1988) suggests different reasons for textbook assessment. It provides good knowledge of a book's content and helps teachers to identify textbook merits and demerits already being used. All the textbooks in ELT should have remarkable features and qualifications, effectiveness, and fitness for people who use them. The evaluation team do not need to be limited to teachers alone. Thus they can be a writer, a teacher, a student, an investigator or an editor.

\section{Evaluation Process}

According to Hutchinson and Torres (1987), evaluation is a decision about the appropriateness of something for a particular goal. There are only degrees of fitness for the needed purpose without being completely good or bad. Furthermore, Hutchinson (1987) considers assessment as a two-way communication process involving a subjective and objective analysis of materials and matching the students' and teachers' requirements with a provided situation. In evaluating materials to decide and judge their usefulness, the evaluation process can start by considering what information to choose and collect, and how and from whom to gather it. As Dudley-Evans and St. John (1998) state, a useful evaluation strongly needs information that:

\section{1- Emphasizes the merits and demerits of the materials}

2- Clears how materials should or should not be applied.

It is obvious that, the results of material evaluation enable material developers to repeat and express strong points and improve weak and less successful parts in the next steps of the revision of the materials. According to Frechtling Westat (2002), the US National Science Foundation (NSF), evaluation is a unique and single part of the process of material development, rather than as an effort directed alone at the end of a work.

\section{Textbook Evaluation Criteria}

Tomlinson (1999, p. 11) believes that there is not one sample plan for textbook evaluation, "the framework used must be determined by reasons, objectives and circumstances of the evaluation". Garinger (2001) shows the value of providing a checklist or using of it for evaluating textbooks. A number of features and criteria for a good textbook, according to Ansary and Babaii (2002, p. 6) are as follows:

1- Dissemination of a vision, theory or approach, about the nature of language.

2- The nature of learning and how the theory can be put to applied use.

3- Stating purpose(s) and objective(s) for the total course and for individual units.

4- Selection and its rationale for coverage, grading, organization and sequencing.

Cunningsworth suggests four below Criteria for textbook evaluation: 
1- They should correspond to learner's needs. They should match the aims and objectives of the language learning program

2- They should reflect the uses, present or future, which learners will make of the language. Textbooks should be chosen that will help equip students to use language effectively for their own purposes.

3- They should take account of students' needs as learners and should facilitate theirlearning with processes, without dogmatically imposing a rigid method.

4- They should have a clear role as a support for learning. Like teachers, they mediate between the target language and the learner.

\section{Method}

This study was a textbook evaluation. It was undertaken to evaluate the merits and demerits of Iranian first year high school English textbook. More specifically, the present study sought to find answers to the following questions:

1- What are the objectives of high school first year English textbook?

2- What are the strengths and weaknesses of the Iranian high school first year textbook?

3- To what extent does this textbook satisfy needs and wants or meet students' general needs in terms of how to learn and what to learn?

4- How can this textbook be improved in order to be useful both to the students and teachers?

\subsection{Design of the Study}

In this study, data were obtained by quantitative (questionnaire) and qualitative methods (interviews). The use of mixed method approach - a combination of both quantitative and qualitative approaches - is the major strength of this research design. Triangulation, the use of multiple data collection methods, data sources or theories as corroborative evidence for the validity of research findings, helped to eliminate biases that might result from relying exclusively on one data collection method (Gall et al., 1996).

\subsection{Context of the Study}

The study was carried out in four high schools in Tabriz, Iran: Ehsan, Fatemeh Zahra, Tohid, and Farzanegan. It should be mentioned that three of these schools were for girls and one school was for boys.

\subsection{Material/Textbook}

Under the auspices of the Ministry of Education, four English textbooks have been developed for the four levels of high school in Iran. They are titled English Book One, Book Two, Book Three and Book Four. In this study and in order to be more specific, the researchers selected and focused on the English book 1 which is taught in the first grade of Iranian high schools. This book was used as the material to be evaluated.

In this coursebook, each lesson includes the following sections or components:

1. New words.

2. Reading section, which is a set of reading passages followed directly by a series of comprehension questions. The two parts of 'New Words' and 'Reading' are the core sections of the textbook.

3. Grammar and Writing Exercises.

4. Language Function.

5. Pronunciation Practice.

6. Vocabulary Drills.

\subsection{Participants of the Study}

The participants for this study consisted of all the four high school English students in second grade and their English teachers in Tabriz who are teaching English at high schools at present. The sample included 126 high school second year English language students. The participants of the questionnaire were both female and male and the age range of all the learners who took part in this research was between 14 and 15 .

Also, the other participants of this study were high school English language teachers. The teachers were both male and female from four high schools and all of them had more than five years of teaching experience. Their teaching experiences ranged from 5 to 19 years. Two of these teachers had nineteen years of teaching experience. Meanwhile, the other three teachers had taught English for at least five years. These five teachers were between 38-50 years old. They were asked to reflect on the efficiency of the first English language textbook currently in use at high schools in 
Iran by answering the questionnaire and interview items. Among the total of 126 participants, about $20 \%$ of them were males and $80 \%$ were females. The majority of the participants (97\%) in this study were students and only $3 \%$ were teachers.

\subsection{Instruments}

The instruments in this study consisted of questionnaires and interviews. In an attempt to elaborate on evaluating first year high school English textbook, the first instrument that was utilized as the data collection tool in the present study was a questionnaire. Questionnaires were given in order to gain insights into the students' perceived needs, experienced teachers' expectations of the book, and other relevant details. The second instrument included an interview. The interviews were conducted with five experienced teachers and ten students.

\subsection{Evaluation Criteria}

To conduct the evaluation and due to lack of time and ease of administration a checklist was used. This checklist consisted of 13 characteristics which are presented below:

1. Explicit statement of the objectives in the introduction and their implementation in the material.

2. Good vocabulary explanation and practice

3. Acceptable approaches to educational and social target community.

4. Periodic review and test sections.

5. Appropriate visual materials available.

6. Interesting topics and tasks.

7. Clear instructions.

8. Clear attractive layout, print easy to read.

9. Content clearly organized and graded.

10. Plenty of authentic language.

11. Good grammar presentation and practice.

12. Fluency practice in all four skills.

13. Encouraging learners to develop own learning strategies and to become independent in their learning.

\subsection{Questionnaire}

The questionnaire consisted of thirty four multiple-choice items. The items of questionnaire were in the form of five-point Likert scale: strongly disagree $(S D=1)$, disagree $(D=2)$, unsure $(U=3)$, agree $(A=4)$, and strongly agree $(\mathrm{SA}=5)$. They were distributed by the researchers to the students. The closed-ended items were written in a manner to survey and find out information and all the facts about the following sections of the textbook: appearance of the book, different topics and texts, vocabulary items, grammar points and exercises, pronunciation practice, language functions, cultural and social aspects.

\subsection{Interview}

In order to support the questionnaire results, and increase the outcomes of the research, the researchers carried out the interview to talk directly with teachers and students. The interviews were conducted with a selected number of students $(\mathrm{n}=10)$ and five teachers. The participants were free to choose Farsi or English language in order to respond to the interview questions. The interview questions consisted of fourteen open-ended items. The amount of time required to respond to the open-ended items was exactly twenty five minutes. The open-ended items were intended to elicit the participants' opinions regarding the high school English book 1 and how it could be improved in order to fulfill the students' needs and teachers expectations and also curriculum goals. These items focused on the merits and demerits of the textbook and consisted of both general and detailed items about the textbook.

\subsection{Data Analysis}

Through performing a page-by-page analysis of evaluative checklists and students and teachers' responses to questionnaire and interview, the collected data were analyzed both quantitatively and qualitatively. The checklists adopted for textbook analysis provided us with the frequency and the percentage of the number of references to 13 items in checklist. The students' opinions and the teachers' attitudes toward the textbook's content and its strengths and weakness were analyzed statistically and interpretatively.

\subsection{Analysis of the Questionnaires}

For analyzing the survey data collected by means of the questionnaire, first the answers were quantified. Each 
option of the items was ranked (strongly disagree $(S D=1)$, disagree $(D=2)$, unsure $(U=3)$, agree $(A=4)$, and strongly agree $(\mathrm{SA}=5)$. In order to provide a clear picture of the responses given to the 34 items of the questionnaire, the items were grouped together and analyzed for making the analysis easier (physical make-up, vocabulary items, topics and contents, grammar points and exercises, language skills, pronunciation practice, and language functions \& social and cultural activities). The individual items of the questionnaire were in fact grouped together in sections and analyzed based on the median of the answers given to them. Then, the information which was collected with the questionnaire was analyzed through SPSS. The other two measures of central tendency, mode and mean, were also reported based on this assumption. Frequency counts and percentage of the answers given to the items in each one of these seven categories were also calculated.

\subsection{Analysis of the Interviews}

After collecting data and transcribing the interview responses, the data were interpreted to produce the findings of the study. The results of analysis and interpretations are presented in the form of frequencies and percentages. In each of these tables and graphs the ultimate results for Iranian first year English textbook for both of the evaluations are given together to be easily compared. In each section of the evaluation, the interpretation of the results are followed by some discussions. The main focus of these discussions is to evaluate the textbook according to the scores given by the participants. Although the obtained scores and percentages given can be evidently interpreted by the reader, the researchers have stated their own interpretations of the results regarding the strengths and weaknesses of the textbook.

The major results of students' and teachers' responses to the interview questions showed that the vast majority of the answers given to the interview questions were to some extend similar. The following analysis contains the results of the interviewees' expectations:

T1: The textbook should provide good techniques for English learning and teachers should learn to use these techniques in their classrooms.

T2: It should familiarize and provide students with pair work activities and more discussions so that it can develop the students' communicative abilities.

T3: It should develop the students' communicative abilities and help them to develop all four skills including reading, writing, listening, and speaking.

S1: It should contain exercises and practices that could motivate the learners. It should pay attention to both educational and emotional aspects.

Students' responses toward the physical appearance and layout of the textbook revealed that they prefer real photos. Moreover, the pictures should be relevant to the language content; otherwise, the students might get confused or lose interest. In addition, the students contended that there is not much information related to the learning methods or strategies presented in the textbook. They were able to remember pronunciation practices. The students' interviews revealed that they liked a variety of topics. They preferred the topics which were relevant to the current issues, famous people, animals, and their lives. Furthermore, the survey results showed that students liked stories. So, the major findings of the interviewees' responses led us to conclude that the English book 1 is not desirable and effective for the learners needs.

\section{Summary of the Results}

Based on the above mentioned 13 criteria, the total number of units in either section of the textbook was examined. As the data make it clear and considering the mean values, the mean value of the layout of the book was 3.02; the mean value of the vocabulary was 3.31; the mean value of the grammar exercises was 3.26 ; the total mean value of the language skills was 3.10 which includes reading skill $(\mathrm{m}=3.17)$, listening skill $(\mathrm{m}=2.96)$, writing skill $(\mathrm{m}=3.22)$, and speaking skill $(\mathrm{m}=3.11)$; the mean value of the pronunciation practice was 3.20 ; the mean value of the language function, social and cultural activities was 2.67. These scores are to some extend median or are equaled with unsure in the intended spectrum. It is clear that, in spite of the little difference (significant or non-significant), none of these cases can be considered as a strength point of this book. Other issues such as listening skill, social activities, and culture can be counted as weak points of the book 1 . This is because the foreign language culture is completely different from the Iranian culture and most writers such as McGrath (2002) and Chastain (1988) support the idea of teaching the culture of a foreign language.

As a whole, the results of this study revealed that English book 1 is structure based and it cannot meet the curriculum goals and students' needs. In this book only reading skill is emphasized and communicative role of the language is ignored. Meanwhile, there is no focus on the culture of foreign language countries and does not provide students with suitable expressions in different cultures in order to know other countries' customs and know the 
culture of other people. The authors of textbook 1 can enhance the learning process through the creation of variety and attractiveness and use of supplementary materials and visual aids.

\section{Responding to the Research Questions}

After collecting the data and analyzing them in the previous section, the research questions of the study are answered as follows:

Research question 1: What are the objectives of high school first year English textbook?

The main goal of all English textbooks which are taught in Iranian high schools is to develop students' communication abilities. Nonetheless, the results revealed that the English textbook (1) could not help students reach this goal and, consequently, solve their communication difficulties in English. Indeed, there are many dialogues in the book which show the English language usage, but, do not focus on the uses of English in actual situations. They do not seem to be communicative. They are only used to present the grammatical rules and points. Therefore, it cannot develop the students' communicative competence. Therefore, the students are not able to use the language appropriately in different situations and contexts outside the classroom. A good classroom situation itself can be a useful means of encouraging communication. Moreover, in order to provide more opportunities for communication, the textbook writers should include different oral and reading texts. Involving students in different group work and pair work activities and helping them interact with other members of the class motivate them to learn, communicate effectively, and develop their communicative abilities.

Research Question 2: What are the strengths and weaknesses of the Iranian high school first year textbook?

The main purpose of this study was to evaluate the English coursebook (1) in order to find out its merits and demerits. Considering the findings of the study, it became clear that there were different opinions and comments about the strengths and weaknesses of the textbook. After analyzing the students' responses to the survey questions and the teachers' and students' interview transcripts, the weak points of the English textbook (1) were deduced. The weaknesses of this book are presented and discussed in the following paragraphs.

First, one of the most important weaknesses of the Iranian high school English textbook is that it is taught in the students' native language, i.e. Farsi language. In Iranian high schools teachers use Farsi language to teach learners, believing that by teaching students in their native language they would understand the lessons better. Some of them even use learners' mother tongue, Azeri, for teaching. The problem of teaching in this way is that it makes students unable to speak fluently and communicatively because one of the practical ways of making progress and being communicatively competent is communicating in the target language from the beginning of the instruction.

Teachers even usually use Farsi to describe drill models, give examples, or explain the meaning of difficult activities. Indeed, the only activity which is conducted in English is the reading part and other parts of the book, including grammar points such as tenses, active and passive verbs, direct and indirect object, and adverb and adjective, are presented in Farsi. In the class and in order to teach a lesson, first of all, teachers read the text and then translate it into Farsi. This kind of translation prevents the students from further effort and thinking.

The second problem is related to the teaching of new words. Teachers usually provide the students with the words and their equivalents in Farsi and the students learn them by repetition and memorization without understanding. This learning is a kind of rote learning which can be replaced by different meaningful activities. To teach new words, teachers can use pictures, give real examples, or make use of role play. Another problem, related to the vocabulary section, is that they are presented in one lesson and are not repeated and used in preceding and following lessons. As a result, students lose the opportunity to see the words in different contexts, and, consequently, forget the presented words very quickly.

The third problem is related to the phonology and pronunciation practice. In spite of the fact that there are phonological differences between English and Farsi languages, these differences are not considered in the textbook. For instance, although Farsi language does not have English sounds such as $w$, th, and some vowel sounds, they are ignored in the coursebook.

The forth problem is related to the skills. The four language skills, reading, writing, speaking, and listening activities, are not equally attended to. Indeed, although the book is to develop reading and writing skills, the true writing is needed. In this book, the intention of writing activities is to practice the grammatical structures. The book does not include authentic writing activities such as writing a letter to the teacher, to a friend, and to parents. In addition, the coursebook is not supported by audio or video activities for listening purposes.

The fifth problem is related to the underlying theories and methodology of the coursebook. From this point of view, it is totally different from the common learning and teaching theories (Brown, 1995; Cunningsworth, 1995; Harmer, 
1996; Sheldon, 1988; Williams, 1983). It is obvious that the English coursebook (1) is structure-based. The syllabus designers do not give importance or attention to the possibility of incorporation of the target language components, such as vocabulary, grammar, and pronunciation, and skills which are thought to be the main goal of teaching and learning English.

The sixth problem is related to the layout of the book. There are no visual aids such as pictures, no use of different colours, and no type of illustrations, which can help students to understand, learn, or remember information better. Devices which are related to visuals can be useful and encouraging. According to Cunningsworth (1984, p. 57), "what we should look for is a good balance between visual material and written text, so that each supports the other". Thus, lack of enough visual aids makes the lessons boring. Meanwhile, the plan of the physical appearance of the book lacks variety and is unclear and unreal. Some boring activities can be made interesting through the use of visual support and real layout.

The last problem is related to the objectives for which the book has been written and published and the unfamiliarity of the students with those objectives. Although students do not easily notice the main goals of the book, they do its exercises. Some of the high school teachers cannot change the classroom activities in order to make them suitable for students' needs. They do not have any plan except conducting the book activities. Some experienced teachers, who have a plan for their classes, arrange and make some changes so that it can be made useful for students. More than half of the students react with interest to the teachers' effective classroom programs.

In spite of the above mentioned weaknesses of the book, it has some strengths that can be summarised as follows:

- More attention on reading and writing,

- Focus on accuracy,

- Presentation, Practice, and Production,

- Focus on language structures,

- Grammar-oriented.

The activities related to the language structure of the book play the role of providing a framework for limited language activities. Cunningsworth (1984, p. 18) states that "Grammar is immensely important, being the system of rules for the formation of correct sentences and it is essential that learners are able to both understand and use the rules of grammar".

Research Question 3: To what extent does this coursebook satisfy needs and wants or meet students' general needs in terms of how to learn and what to learn?

Hutchinson and Waters (1987) separate target needs from learning needs. Based on them, the first one asks the students' opinions about the learners' duties in target context and the second one asks the needs and wants of students for learning. Language need is the main requirement of the target needs. Attention to learning needs causes students to flower in a successful way. It also makes the learning easier.

It is believed that the first year high school English coursebook cannot assist learners to successfully achieve their desired goals. In English book 1, the subjects and texts should meet learners' requirements and interests and encourage them to participate in the classroom practices and in the learning processes. It was indicated that most of the reading passages of the coursebook are not appropriate for the students' ages and are not encouraging enough. In addition, this book is not developed according to the different Iranian students' desires, cultures, and language learning goals. Iranian students, who are from different cities and towns, are different according to their cultural backgrounds and mother tongues.

Furthermore, some of the learners study in villages and their teachers are novice and have no access to other sources of information and the coursebook is their only source of information. On the other hand, other students can make a good progress by attending private classes. Thus, the first year coursebook's practices and exercises do not satisfy learners with different interests and needs. For example, some students are interested in learning English to interact and communicate with native speakers of the language and this book does not meet their needs. There are some students who learn English to pass the university entrance examination. For this reason, they only pay attention to the particular parts of coursebook such as grammar rules, reading comprehension, and vocabulary without paying any attention to the other three skills. In addition, there are some who are not interested in participating in the classroom activities. They only want to pass the course. The results of the current study confirm this claim.

It can be concluded that in Iranian high schools, teachers have the main role of following what to teach and how to teach. In this system, the learners are only listeners and followers. They imitate teachers' behaviour or follow exactly the way their teachers do things. So, they have no role in the instruction and they only repeat the words and 
structures of the coursebook.

Research Question 4: How can this coursebook be improved in order to be useful to the students and teachers?

One way of making an educational program better is to change the coursebook materials. According to Cunningsworth (1995) and Ellis (1997), coursebook evaluation aids teachers to use effective, correct, and organized ways of dealing with materials. Considering the high school book's content, it can be inferred that from the four skills two of them, reading comprehension and writing, are given more attention. Students are not provided with the opportunities to develop the other two skills. The skills that are present in the book do not include various listening and speaking skills which make students discuss or talk with each other.

In order to use the existing book more efficiently, teachers should apply suitable techniques. For instance, as mentioned in the previous sections, nearly all of the English teachers read the passages and translate them to Farsi and give the meanings of difficult and unknown vocabularies in Farsi. Thus, learners have no need for studying the text. Since the reading passages are the main section of each lesson of the book, decision-makers can change the content of these passages. For example, the suitability of the reading content is a motivating tool to encourage students and it can be changed to be suitable for the students' needs and interests. Or the arrangement of reading texts according to the difficulty level is an important factor in encouraging students to work on reading materials. In addition, the amount of time given to class should be increased to three or five sessions in a week.

\section{Conclusion}

Based on the information obtained in this study, it is possible to identify several factors that affect what type of coursebook material should be used in a given situation like Iran for first year high school English students. Coursebooks are one of the very essential components of language instruction. Students learn what is presented in the coursebook. They make students to enjoy learning English and to become successful in learning. According to Williams (1983, p. 254), "the coursebook is a tool and the teacher must know not only how to use it but how useful it can be."

With regard to coursebook evaluation, it was found that the focus of the English coursebook (1) is mostly on grammatical points, memorization of new words in isolation, and reading through some passages and answering related questions. Referring to the findings and to successfully solve the problems, the coursebook users, especially teachers, should give special and equal attention to the four skills and engage learners in the classroom activities and to make them learn to use the language for communication. The book's tasks should be written in a way that the students can use them on their own. And for the purpose of helping the teachers to teach effectively and successfully, there should be a teacher's book. In order to enhance the amount of learning, the application of language teaching tools such as films, DVDs, and computer are suggested. So, making simultaneous use of these means can make a big progress in the language learning program. To sum up, this coursebook cannot meet the students' and the teachers' needs within the Iranian educational system. It is structure-based and it ignores the communicative role of the language.

It is hoped that the authors of the book add more suitable learning activities in high school English book (1) to expand and increase the communicative ability of the students. At the end, it is interesting to conclude with Cunningsworth (1984, p. 89):

No coursebook will be totally suited to a particular teaching situation. The teacher will have found his own way of using it and adapting it if necessary. So, we should not be looking for the perfect coursebook which meets our entire requirement, but rather for the best possible fit between what we as teachers and students need.

\section{References}

Ansary, H., \& Babaii, E. (2002). Universal characteristics of EFL/ESL coursebook: A step towards systematic coursebook evaluation. The Internet TESL Journal, 2, 1-8.

Birjandi, P., Soheili, A., Noruzi, M., \& Mahmudi, G. (2006). English book 1. Tehran: Iran Publications.

Brumfit, C. J. (1980). Seven last slogans. Modern Language Journal, 7(1).

Chastain, K. (1988). Developing second language skills: Theory and practice. New York: Harcourt Brace Jovanovich.

Crystal, D. (2003). English as a global language. Cambridge: CUP. http://dx.doi.org/10.1017/CBO9780511486999

Cunningsworth, A. (1984). Evaluating and selecting EFL teaching materials. London: Heinemann Educational Books.

Cunningsworth, A. (1995). Choosing your coursebook. Oxford: Heinemann. 
Davison, W. (1975). Factors in evaluating and selecting texts for the language classroom. ELT Journal, 30(4), 310-314.

Dudley-Evans, T., \& St John, M. J. (1998). Developments in English for specific purposes. Cambridge: CUP.

Ellis, R. (1997). The empirical evaluation of language teaching materials. ELT Journal, 51(1), 36-41. http://dx.doi.org/10.1093/elt/51.1.36

Frechtling W. J. (2002). The 2002 user-friendly handbook for project evaluation. Arlington, VA: National Science Foundation.

Garinger, D. (2001). Coursebook evaluation. TEFL Web Journal 1(1). [Online] Available: http://www.teflweb-j.org/v1n1/garinger.html

Giaschi, P. (2000). Gender positioning in education: A critical image analysis of ESL coursebooks. TESL Canada Journal, 18 .

Hutchinson, T. (1987). What's underneath? An interactive view of materials evaluation. In L. E. Sheldon (Ed.), ELT coursebooks and materials: Problems in evaluation and Development. ELT Documents 126. London: Modern English publications. The British Council.

Hutchinson, T., \& Waters, A. (1987). English for specific purposes: A learning centered approach. Cambridge:CUP. http://dx.doi.org/10.1017/CBO9780511733031

Jordan, R. R. (1997). English for academic purposes: A guide and resource book for teachers. Cambridge: CUP.

Masuhara, H., Hann, N., Yi, Y., \& Tomlinson, B. (2008). ELT Journal, 62(3), 294-312.

McGrath, I. (2002). Materials evaluation and design for language teaching. Edinburgh: Edinburgh University Press. Nunan, D. (1999). Second language teaching and learning. Boston: Heinle and Heinle.

Razmjoo, S. A. (2007). High schools or private institutes coursebooks? Which fulfill communicative language teaching principles in the Iranian context? Asian EFL Journal, 9(4).

Richards, J. C., \& Rodgers, T. S. (2002). Approaches and methods in language teaching. Cambridge: CUP.

Sheldon, L. (1988). Evaluating ELT coursebooks and materials. ELT Journal, 42(2), $237-246$. http://dx.doi.org/10.1093/elt/42.4.237

Tomlinson, B. (1999). Developing criteria for materials evaluation. IATEFL Issues.

Tomlinson, B. (2001). Materials development. In R. Carter, \& D. Nunan (Eds.), The Cambridge guide to teaching English to speakers of other languages (pp. 66-71). Cambridge: CUP.

Tomlinson, B. (Ed.). (2003). Developing materials for language teaching. London: Continuum.

Tomlinson, B. (2006). Localizing the global: Matching materials to the context of learning. In J. Mukundan (Ed.), Readings on ELT materials II (pp. 1-16). Malaysia: Pearson Longman.

Tomlinson, B. (Ed.). (2008). English language learning materials: A critical review. London: Continuum.

Williams, D. (1983). Developing criteria for coursebook evaluation. ELT Journal, 37(3), 251-255. http://dx.doi.org/10.1093/elt/37.3.251

Y1lmaz, C. (2005). The contribution of selecting and evaluating coursebooks to language teaching and learning in EFL classroom. Kastamonu Education Journal, 13(1), 265-272.

Zohrabi, M. (2011). Coursebook development and evaluation for English for general purposes course. English Language Teaching, 4(2), 213-222. http://dx.doi.org/10.5539/elt.v4n2p213 